\title{
Lived experiences of HIV community workers participating in a community empowerment programme
}

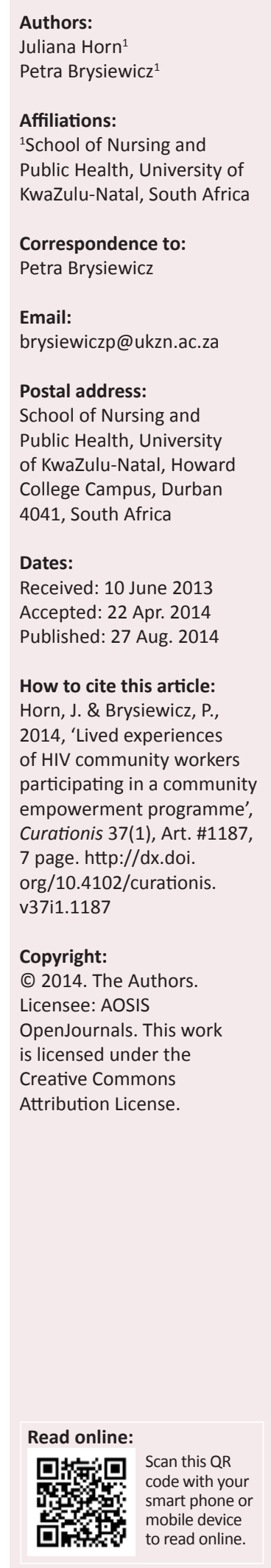

Background: Both non-governmental organisations and governmental organisations are very involved in the development and implementation of community empowerment programmes (CEPs). Because of various health issues within the community, 10 CEPs were launched in Ladysmith with a focus on addressing the particular needs of HIV-affected and -infected members. Of the 10 programmes, however, only four were deemed sustainable after five years.

Objectives: The researcher explored the lived experiences of HIV community workers participating in two CEPs in Ladysmith, KwaZulu-Natal in order to develop recommendations for CEPs.

Method: Data were explored using a qualitative hermeneutic phenomenological approach. Ten participants who had been involved in HIV CEPs for more than six months were identified and individual interviews were held.

Results: Three themes emerged, namely, giving of yourself, maintaining sustainability and assisting the CEPs and community workers. Each of these themes also contained a number of subthemes. Exploring the lived experience of the community workers revealed that there are a number of ways in which to promote the sustainability of CEPs.

Conclusion: The community should be involved in all aspects of the CEP and community workers must respect the community and their knowledge, experience and value systems.

\section{Introduction}

During the past 15 years, community empowerment has become an important point of focus in international funding for both government organisations (GOs) and non-governmental organisations (NGOs), with the emphasis on community empowerment programmes (CEPs) involving community workers (CWs) and health workers (Chan 2008; Hartwig, Humphries \& Matebeni 2008).

In 1994, South Africa committed itself to a Primary Health Care approach in its delivery of health services (African National Congress 1994). Personnel, budget and resource constraints saw both NGOs and GOs uniting against HIV, unemployment, education, poverty, teenage sexual activities, nutritional needs and shortcomings in services provided by the Departments of Health, Agriculture and Social Services. In 2009, the AIDS Foundation of South Africa reported that the shortage of health professionals, resources and infrastructure had a negative impact with regard to reaching the Millennium Development Goal objectives, making it difficult to sustain optimal healthcare (Department of Health 2013). According to a report by Ncayiyana (2010), achieving the targets for preventative care by 2015 hinges on access to primary healthcare. The Millennium Development Goal targets could not be reached unless communities, NGOs and GOs united in setting up CEPs with funds that became available from both government and the private sector (Ncayiyana 2010).

\section{Problem statement}

In the rural low-income areas in the vicinity of Ladysmith, numerous CEPs have been launched at various times by GOs and NGOs, some continuing in the long term, whilst others lasted only for as long as the original driving force (people) remained involved in the programme. A total of 10 CEPs was launched, focusing on the particular needs of HIV-affected and -infected members, the youth, the elderly and poverty. Five years from their inception, four CEPs were demonstrably sustainable. Two CEPs continued to expand their services within the borders of their project locations and seemed to offer useful models for emulation. Both of these CEPs are community 
driven and their respective communities accepted full responsibility for all services rendered and the management of resources. A desire to understand the dynamics of these two CEPs and the lessons they could provide was what first prompted this research. The researcher was interested in what sustains certain CEPs and keeps the role players motivated, as well as whether it is possible that certain implementation steps could improve their success and boost retention of individual CWs. The recommendations that emerge from exploring the experiences of the CWs in the two successful CEPs could assist future community nurses, health professionals, CEP developers and NGOs to retain personnel and maintain successful CEPs.

\section{Research objectives}

The research objectives of the study were as follows:

- To explore the lived experience of community workers participating in two HIV community empowerment programmes in Ladysmith.

- To develop community empowerment programmes recommendations based on the lived experience of participants in the two community empowerment programmes.

\section{Definition of key concepts}

For the purpose of this study, a community empowerment programme (CEP) refers to a programme that provides psychosocial and educational upliftment, economic empowerment, life-skills development and an improved standard of living in a given community. A community worker (CW) refers to any one of a group of people (both medical and non-medical) who offer their time, skills and resources voluntarily to the CEP (with or without remuneration). Community empowerment programme sustainability refers to a programme that has been in place for more than five years and which has continued to deliver or expand the services that were outlined initially by the respective goals of the CEP.

\section{Research method and design Design}

The researcher explored the lived experience of $10 \mathrm{CWs}$ in two sustainable HIV CEPs in Ladysmith, KwaZulu-Natal by means of a study which followed a qualitative hermeneutic phenomenological approach (Van Manen 1997).

\section{Data collection method}

A convenience sample was used in this study and the researcher approached the current team leaders of the two identified CEPs, who then suggested potential participants and facilitated opportunities for the researcher to explain the inclusion criterion, purpose and data collection process to the prospective participants.

The inclusion criterion stipulated that only persons who had been involved for at least six months in the two programmes could be selected as participants. The team leaders of each of the CEPs were included as well as four CWs within each programme. These four CWs in each CEP comprised one medical officer, one nursing personnel and two nonmedical community workers. The diverse backgrounds and educational levels of the participants meant that valuable data could be collected from a wide range of perspectives.

The researcher appointed a local isiZulu-speaking resident as a research assistant, who was trained in research confidentiality and interviewing skills. Individual meetings were set up with the 10 participants at a venue of their choice between June 2012 and December 2012. Rapport was established during the first contact with each participant, as the researcher and research assistant engaged them in informal social conversation until such time as the participant felt comfortable and seemed at ease. A minimum of two individual interviews was conducted with each participant and they were audio recorded with their permission. All of the participants were interviewed in the language of their choice (English or isiZulu) and the researcher and the research assistant were present at all interviews. Datacollection interviews continued until no new themes emerged. All the interviews were transcribed verbatim and isiZulu interviews were then translated into English. These transcripts were then checked by the Language Department of a local university in order to ensure correct transcription and translation from isiZulu to English. Certain difficulty was experienced when translating the transcripts, particularly in relation to conveying certain key words and concepts, for example, 'sustainability' and 'empowerment'.

\section{Data analysis}

Data analysis was guided by the phenomenological reduction steps for analysing the data (Van Manen 1997), which included the researcher ensuring that questions and responses in the interviews were transcribed verbatim and that non-verbal behaviour was recorded. Delineating units of meaning was when the researcher considered the literal content, the number of times a unit of meaning was mentioned (its significance) and how the unit of meaning was stated. Clustering of units of meaning to form themes was then done. Themes and subthemes were extracted from the interview as a whole and care was taken not to cluster common themes if significant differences were apparent. A watch was kept for unique or minority voices (Groenewald 2004). The researcher conducted a validity check by returning to each participant to determine if the essence of the interview had been captured correctly (Van Manen 1997).

\section{Results}

Data were collected from 10 participants involved in the two CEPs; all the participants identified by the CEP team leaders agreed to participate in the research. Four men and 6 women participated, ranging in age from their 20s to more than 70 years old. Table 1 contains the demographic profile of the participants.

Three themes emerged from the data, namely, giving of yourself, maintaining sustainability and assisting the CEPs and CWs. Each theme had a number of subthemes (refer to Table 2). 
TABLE 1: Demographic profile of participants.

\begin{tabular}{|c|c|c|c|}
\hline Participant pseudonym & Age & Gender & Description \\
\hline Pat & $50 \mathrm{~s}$ & Female & Pat is a health professional with prior experience in community services. \\
\hline Thabani & $30 \mathrm{~s}$ & Male & Thabani is a volunteer who has been involved in the CEP since 2008. \\
\hline Neliswa & $20 \mathrm{~s}$ & Female & $\begin{array}{l}\text { Neliswa enrolled in the community empowerment programme in 2008. She has a specific interest in community } \\
\text { projects that address the needs of orphans and children. }\end{array}$ \\
\hline Joanne & $50 \mathrm{~s}$ & Female & Joanne is a health professional with prior experience in mobile clinic services. \\
\hline Themba & $50 \mathrm{~s}$ & Male & Themba was recruited in 2003 as a volunteer. \\
\hline Lindiwe & $40 \mathrm{~s}$ & Female & Lindiwe has a special interest in orphan care and was recruited in 2008 as a volunteer. \\
\hline Swenkie & $60 \mathrm{~s}$ & Male & Swenkie was recruited in 2006 and entered as a volunteer addressing the needs of the elderly. \\
\hline William & $60 \mathrm{~s}$ & Male & William was recruited 4 to 5 years ago. He approached the programme director and volunteered his services. \\
\hline Norah & $70 \mathrm{~s}$ & Female & Norah was recruited as a volunteer approximately 8 years ago. She entered the programme via the elderly craft programme. \\
\hline Ntombifuthi & $30 \mathrm{~s}$ & Female & Ntombifuthi was recruited as a volunteer in 2007 . She entered the programme via the Care giver programme. \\
\hline
\end{tabular}

CEP, community empowerment programmes.

TABLE 2: Themes and subthemes uncovered in this study.

\begin{tabular}{ll}
\hline Themes & Subthemes \\
\hline Giving of yourself & Responding to a need \\
& Passionate engagement \\
\hline Maintaining sustainability & Community ownership \\
& Seeing the results \\
& Careful selection of volunteers \\
& Monitoring and evaluation \\
Assisting the community empowerment & Respect and trust \\
programmes and community workers & Upskilling \\
& Reducing community dependency \\
\hline
\end{tabular}

\section{Giving of yourself}

The participants described their experiences within the CEP as giving of yourself and this was subdivided into two subthemes, namely, responding to a need and passionate engagement.

\section{Responding to a need}

The participants explained that attending to the various needs of families in the community was important for them and that, as a member of the same community, they could no longer ignore what was going on around them.

\section{A non-medical CW shared:}

'It has been so hard to see children experiencing this life, like when you grow up and [not] have any one around you to guide you, to feed you, even to dress you ... anyone to go to take you to school.' (Neliswa, Female, 20s)

A health professional explained:

'One day when a child was looking for food and asked its [her] ailing mother to prepare food [as she was hungry]. [It] really made me decide that people need support closer to them.' (Pat, Female, 50s)

She also described an incident that motivated her to get involved:

'One person was put in a tin house where food would be pushed to him, because people were scared he would infect them.' (Pat, Female, 50s)

\section{Passionate engagement}

The participants displayed total commitment to the community and persevered under difficult circumstances. A non-medical CW explained:
'Initially it was very bad. I found that the community [community members] was very sick. It was difficult to get transport to go to clinics. They [mobile service points] wanted the person [patients] to come to them. You find others that are sick, they cannot even stand, others they are on the bed [bedridden]. We used wheelbarrows.' (William, Male, 60s)

This CW described further to the researcher how he would spend much of his time in the community transporting people to the clinic in a wheelbarrow.

A health professional also described the following:

'Volunteers took food from their [own] households and give to whomever. They [patients] don't have food [and] can't take medication on an empty stomach.' (Joanne, Female, 50s)

\section{Maintaining sustainability}

Four subthemes emerged from this theme, namely, community ownership, seeing the results, careful selection of volunteers and monitoring and evaluation.

\section{Community ownership}

Participants explained how community ownership was achieved. A community meeting was requested and activities and funding of the proposed CEP were discussed in full. The CEP addressed the needs of the community as understood and prioritised by the community itself. The community was involved in the CEP's planning process and was crucial with regard to identifying the disease profile. The CEP did not exclude anyone, did not create false expectations and ensured equity in the distribution of resources.

A non-medical CW expressed the following:

'You can't just go around the community [without gaining] consent [from] the indunas or the counsellors. You have to follow each and every channel that is within that community. If the leaders even don't know who's working in their community they will [view it as] scams.' (Thabani, Male, 30s )

A health professional said:

'If you want to establish a committee for the community find [a] leader who they think should be there and then make suggestions.' (Pat, Female, 50s ) 
Another health professional agreed:

'The most important thing is to find as much out from them [the community] as possible. Give them time to voice. You can't meet the whole community, you meet the representatives.' (Joanne, Female, 50s)

\section{Seeing the results}

The successes of the CEP motivated CWs to remain involved in its endeavours, whilst at the same time encouraging community members to approach them for assistance and advice.

\section{A health professional reflected:}

'People saw results. Patients who were not able to walk at the start on treatment, because of their low CD4 count. Now they [patients] are standing up walking, gaining weight and being prepared to lead and talk about it.' (Pat, Female, 50s )

She went further to say:

They [community members] are [saying] listen you saw me ... I was smelling ... I was this and that and nobody wanted to be next to me. Guys come there...in there is life in accessing treatment [for HIV].' (Pat, Female, 50s)

A non-medical CW commented:

'The project is very special because now children attend school and receive food. This programme works a lot for the orphans.' (Lindiwe, Female, 40s)

\section{Careful selection of volunteers}

Participants emphasised the importance of community leaders assisting with the selection of CWs in terms of agreed-upon criteria. CWs selected would be made known to community leaders and the community at large. The following character qualities were taken into account in the selection process: commitment, caring, sensitivity, respect for the community, maintaining confidentiality, being non-judgemental and being able to persevere in the face of many challenges.

\section{A team leader explained:}

'It is ... it is better if they [CWs] are nominated by the community, they will tell you the characters. You are looking for a person who is confidential. You are looking for somebody caring, humble. Everybody must be comfortable ... happy working with them.' (Thabani, Male, 30s)

A volunteer said:

'Contact people that you trust and can work with. Identify the right people, identify the untrustworthy, the disrespectful. You have to be patient when working with people, greet them even if they don't want to greet back, be courteous, be patient, dress appropriately, walk and be humble. Don't fight with them [patients].' (Norah, Female, 70s)

There was a sense that whereas older CWs stayed in the CEP because of a deep-rooted desire to relieve the suffering of community members, the younger ones were inclined to leave the programme.
A health professional explained:

'The younger female, less than in the [their] thirties are still looking for greener pastures. So yes they can come with their standard tens but if they leave the position for $[a]$ more fruitful [one], you can't stop them.' (Joanne, Female, 50s)

\section{Monitoring and evaluation}

Team leaders compile weekly reports of the services rendered and the resources used and/or requested by CWs and they in turn provide weekly feedback to the team leader.

A health professional explained:

'They [team leader] will report every week and express their concerns talk about challenges, advise, capture the data and [forward] to whatever office. It can be a community member that they select for that particular programme [to give a report], because they $[\mathrm{CWs}$ ] need to give their view of how they see the programme going. The committee will meet like on a monthly basis with the programme director, perhaps on weekly basis meet with the field workers [CWs], recording all the information will help you in future [on] what you need to improve.' (Pat, Female, 50s)

A non-medical CW explained how practical applied monitoring and evaluation undertakings contributed to sustainability:

'Plan the day, like their map. Leave it where they [CWs] are supposed to be, where they sign in, where you will find them. [Do this] because she can just submit whatever then go back to sleep. Carry some sort of a book, write whatever they [CWs] did for the day.' (Thabani, Male, 30s)

\section{Assisting the community empowerment programmes and community workers}

Respect and trust, upskilling and reducing community dependency were highlighted by the participants as being the subthemes making up this theme.

\section{Respect and trust}

The importance of good community relations emerged strongly, with an emphasis on respecting the community and recognising the value of community members' first-hand knowledge.

One of the health professionals responded:

'You have been trained, you are knowledgeable, you have the skills but she knows her community better.' (Joanne, Female, 50s)

Another health professional explained:

'The powerful part is the respect ... when you respect a person the person begins to trust you ... then they can give you all the information you want ... give you all the support you need and you must also be honest with them.' (Pat, Female, 50s)

\section{Upskilling}

Participants emphasised the need for accredited training opportunities supplemented by refresher courses, as these enhanced their skills and maintained their credibility in the eyes of the community. 
A non-medical CW voiced:

'It is very important in $[a]$ disease that you know about it, because like myself I am like a doctor. They say to me, come here we only manage to sweep the house, but it stinks. The gogo has messed herself, but we need someone to go there. I go in there like a doctor. I can take off the dresses put it in the bath, clean her perfectly, put all those things back to normal, then clean the bed, start feeding her without troubles, because of that training.' (Swenkie, Male, 60s)

A volunteer explained:

'They [CWs] will always be updated, whatever is happening so if they do go to the community some of the people in the community they are updated and they will try to test them, how much they know' (Thabani, Male, 30s)

\section{Reducing community dependency}

The participants viewed the reduction of community dependency as an important goal and therefore promoted fund-raising events, effective marketing of the CEPs' services and creation of support groups within the community.

A health professional explained their role:

'You can negotiate and you can say I understand what you want but here is what I am offering you and this is how far I can go.' (Pat, Female, 50s)

A non-medical CW expressed:

'It is to teach the people to feed themselves, work for themselves.' (Swenkie, Male, 60s)

Another volunteer shared his sentiments:

'We not like always [to] depend on receiving. We do not only depend on people to give us money, especially like the funders.' (Thabani, Male, 30s )

\section{Ethical considerations}

Ethical approval was obtained from the Research Ethics Committee of the University of KwaZulu-Natal (HSS/0758/011M) and consent to conduct the research was provided from the CEP directors and team leaders. Participants, after giving written consent, were briefed regarding the proposed research and informed that they could withdraw from the study at any stage. Participants chose pseudonyms and the researcher ensured that data could not be traced back to the individuals.

\section{Trustworthiness}

The researcher pursued the criteria as described by Guba and Lincoln (1994), namely, credibility, transferability, dependability and confirmability. In-depth understanding was explored by the researcher by being present during each contact session with all participants and by becoming familiar to the participants and building a relationship over the seven months of data collection, thus attempting to ensure that rich, useful data were collected. In some cases, the researcher spent a whole day accompanying the participant in the field before interviewing them once they had completed their day's tasks. Data were collected from three different sources of participants (CEP team leaders, health professionals and non-medical CWs), thus ensuring that these different perspectives were taken into consideration. The emerging themes and subthemes were developed and discussed at various stages with the research supervisor (a more experienced qualitative researcher) and also presented to the participants for validation. Thick descriptions of the research process were provided to give the reader a sense of 'being there', to ensure sufficient detail for the reader to follow the path that the researcher took and to then be able to decide if the findings are applicable to other, similar, situations.

\section{Discussion}

The researcher explored which aspects, as perceived by the CWs, contributed toward the sustainability of the two CEPs in Ladysmith.

\section{Giving of yourself}

The non-medical CW involved in the two CEPs saw a need and chose to respond to it with passionate engagement. Participants' responses gave an indication of the level of dedication called for with regard to implementing a CEP. This comes through in details such as having to use wheelbarrows to transport water, planting food gardens, providing home-based care, accessing funds, enduring stigma and maintaining political impartiality. CWs often persevere under very difficult circumstances and participation in these programmes serves to increase their confidence and skills (African Medical and Research Foundation [AMREF] 2008). However, whilst they are motivated and encouraged by the positive changes they have brought about in the lives of community members, they may become discouraged by non-payment, exposure to severe heat, water shortages and lack of resources, accessibility to villages, bad roads, traveling long distances and security aspects (AMREF 2009).

\section{Maintaining sustainability}

Participants explained that community ownership was achieved through consensual and transparent decision making. Amongst the possible community empowerment strategies noted by Blackwell and Colmenar (2000), were strengthening people's capabilities through training, mentoring and peer support; mobilising residents; planning, administration and programme evaluation; managing budgets and human resources; and conflict resolution.

Achieving positive results motivated CWs to stay with the CEP and encouraged community members to approach the CWs for advice or assistance. AMREF (2008; 2009) agrees that volunteers draw motivation and encouragement from witnessing the positive changes they have brought about in the lives of community members. De Souza (2007), whilst studying HIV projects in India, found that volunteers were willing to work incredibly hard for the smallest of gains. It has been suggested that this may be because of the careful selection of volunteers (Kieffer et al. 2004). 
The team leaders monitored services rendered by CWs and the CEP director remained responsible and accountable for all the services rendered within the CEP, including financial and resource management. Leadership development is a primary component of capacity building and in order for these activities to succeed, the leaders' skills must be developed sufficiently and recognised within the community (Nduati \& Kiai 1997)

\section{Assisting the community empowerment programmes and community workers}

The importance of good community relations emerged strongly from a number of the participants, with an emphasis on respect toward the community itself, as well as recognising the value of community members own firsthand knowledge. Nduati and Kiai (1997) caution that a welldesigned programme or policy may fail if it is not based on reality and if it does not have community agreement regarding its importance and activities. In many communities there is a disconnect between the perceived concerns of the community and funding available for community planning. If the community does not see the importance of planning for prevention and control, a real community response is unlikely to emerge, despite the availability of funding. Community awareness and readiness to change may be enhanced by participation in community planning processes and participation in identifying and understanding community health issues and their context. This involvement is regarded as being essential to the success of public health initiatives (Nduati \& Kiai 1997).

CWs in the current study placed value on training because it gave them skills and confidence and heightened their sense of personal motivation and credibility. Traditional and community leaders showed them more respect and they met with increased recognition of the contribution they were making (De Souza 2007). Gibbon, Labonte and Laverack (2002) found that, for community members, capacity building through community empowerment means gaining the knowledge, skills and confidence to improve their own lives.

A point made by Blackwell and Colmenar (2000), which was endorsed by the participants of the current study, was the desirability of reducing dependency on government resources as this was seen as very important for future sustainability. Kieffer et al. (2004) also warn against focusing development efforts solely on one person, or just a few people, whose possible departure could then undermine the whole initiative.

\section{Limitations of the study}

It was feared initially that CWs might feel threatened by the researcher, given that the CEPs were receiving international funding, however this concern soon dissolved as the researcher and CWs won each other's trust.

In addition, when translating the interview questions from English into isiZulu, the researcher experienced difficulty in conveying the meaning of certain key words in isiZulu, for example, 'sustainability' and 'empowerment'. Added to this was the additional difficulty in that English is the researcher's second language. These language difficulties were overcome through the use of the services of the Language Department of the university.

\section{Recommendations}

The data gathered by the researcher (interviews and field notes) were analysed and themes and subthemes were identified. These were then submitted to the participants for validation. These data, together with relevant literature, were then used by the researcher to develop the following recommendations, which were again validated by the participants.

The recommendations for CEPs are as follows:

- Identify and approach the key members within the community: Include the community leaders and traditional leaders.

- Complete a community profile in cooperation with the community: Pay attention to health status, educational level, social activities and current community programmes. Consider traditional values and norms, GO resources, NGO resources and opportunities as identified by the community. Prioritise the challenges that the community faces and the resources that will be required to address them.

- Developing a CEP: Discuss with key community members the opportunities and benefits that a CEP can offer. Be clear about what a CEP can offer the community. Market the CEP effectively.

- Select the CWs with care: Establish the criteria for the selection of CWs, bearing in mind the community's values and norms and the particular challenges facing the community. It is preferable to recruit the CWs from the community and they should be easily identifiable.

- Skilling and upskilling: Train the CWs at an accredited training facility. Record all training sessions attended. Upskill CWs regularly, thereby maintaining their credibility in the community's eyes by ensuring that their knowledge remains current.

- Implementation of the CEP: Explain the duties of the CWs clearly. Compile a map of the visitation points. CWs must report every morning to a central point where they will sign in and receive their daily instructions confirming their visitation points. Support groups must be established within the community.

- Monitoring and evaluation: Appoint a supervisor (team leader) per area from amongst the CWs. The supervisor must monitor and evaluate the services rendered, report problems to the appropriate official(s), offer support/ advice to the CWs and submit a weekly written report to the CEP director. The CEP director must then support and advise them. The CEP director must meet weekly or monthly, as needed, with GO and NGO funders; record all CEP activities; and account for all resources utilised. The CEP director must also update key members of the community and stay alert to their changing needs. 


\section{Conclusion}

Exploring the lived experience of CWs revealed that there are a number of ways in which to promote the sustainability of CEPs. One of the most important aspects for health professionals and CWs is that they need to acknowledge the expertise within the community and be prepared to defer to the first-hand knowledge and experience of the community members they serve.

\section{Acknowledgements Competing interests}

The authors declare that they have no financial or personal relationship(s) which may have inappropriately influenced them in writing this article.

\section{Authors' contributions}

J.H. and P.B. (University of UKZN) were jointly responsibly for conceptualising and carrying out the entire study as well as preparing the article. P.B. was the research supervisor.

\section{References}

African National Congress, 1994, ANC health policy: A national health plan for South Africa, viewed 01 July 2014, from www.africa.upenn.edu/Govern_Political/ ANC_Health.html
African Medical and Research Foundation, 2008, Kenya: John's story, viewed 10 June 2013, from http://reliefweb.int/report/kenya/kenya-johns-story

African Medical and Research Foundation, 2009, Personal stories: Jane's story, viewed 09 June 2013, from http://www.amref.org/news/personal-stories/janes-story/

Blackwell, A.G. \& Colmenar, R., 2000, 'Community-building: from local wisdom to public policy', Public Health Report 115(2-3), 161-166. http://dx.doi.org/10.1093/ $\mathrm{phr} / 115.2 .161$

Chan, M., 2008, 'Return to Alma-Ata', The Lancet 372(9642), 865-866. http://dx.doi. org/10.1016/S0140-6736(08)61372-0

Department of Health, 2013, Millennium development goals: Country report October 2013, viewed 03 July 2014, from http://www.za.undp.org/content/dam/ south_africa/docs/Reports/The_Report/MDG_October-2013.pdf

De Souza, R.T., 2007, 'NGOs and empowerment: Creating communicative spaces in the realm of HIV/AIDS in India', Doctoral dissertation, Graduate School, Purdue University.

Gibbon, M., Labonte, R. \& Laverack, G., 2002, 'Evaluating community capacity', Health \& Social Care in the Community 10(6), 485-491. http://dx.doi.org/10.1046/ j.1365-2524.2002.00388.x

Groenewald, S., 2004, 'A phenomenological research design illustrated', Internationa Journal of Qualitative Methods 3(1), 11-21.

Guba, E.G. \& Lincoln, Y. S., 1994, 'Competing paradigms in qualitative research', in N.K. Denzin \& Y.S. Lincoln (eds.), Handbook of qualitative research, pp. 105-117, Sage, Thousand Oaks, CA.

Hartwig, K.A., Humphries, D. \& Matebeni, Z., 2008, 'Building capacity for AIDS NGOs in Southern Africa: Evaluation of a pilot initiative', Health Promotion International 23(3), 251-259. http://dx.doi.org/10.1093/heapro/dan013

Kieffer, E.C. Willis, S.K. Odoms-Young, A.M., Guzman, J.R., Allen, A.J., Two Feathers, J. et al., 2004, 'Reducing disparities in diabetes among African-American and Latino residents of Detroit: The essential role of community planning focus groups', Ethnicity and Diseases 14(3 Suppl 1), S27-S37.

Ncayiyana, D.J., 2010, 'Millennium development goals: How are we doing', South African Medical Journal 100(11), 689.

Nduati, R. \& Kiai, W., 1997, Communicating with adolescents about AIDS: Experience from Eastern and Southern Africa, International Development Research Centre, Canada.

Van Manen, M., 1997, 'From meaning to method', Qualitative Health Research 7(3), 345-369. http://dx.doi.org/10.1177/104973239700700303 